\section{Emergency departments and minor illness: some behavioural insights}

\author{
Mando Watson, ${ }^{1}$ Mitch Blair ${ }^{2}$
}

The 1999 Report 'Accident and Emergency Services for Children' was published by a collaboration of several Royal Colleges and national organisations, and it was a major driver for accident and emergency departments (ED) to become more expertly child-focused. The paediatric emergency department (PED) provides an environment that is more suitable for young ages, shielding the child and family from the sights, sounds and smells of the adult ED, and staffed by nurses and doctors with specialist child health training.

Yet now, NHS emergency services are creaking under enormous and increasing demands placed on it by the public. In England, $40 \%$ of all ED attendances are non-urgent $(60 \%$ in the case of children), where the unwell person could be self-managed at home. Accident and Emergency (A\&E) attendance costs nearly $£ 100 \mathrm{~m}$ in $2011-2012$ with ED on average being $36 \%$ more than an equivalent general practice (GP) visit.

The waiting time target, introduced in 2004, meant that a patient would be seen, treated and sent on his/her way within 4 hours no matter how ill.

As a result, the PED became quite an attractive option for the worried parent of a child with a non-urgent ailment, who would be almost guaranteed a paediatric opinion within that time period. Maybe PED has become a victim of its own success?

So why do parents bring their children to the PED with minor illness, and what can be done to better understand the drivers and inform potential solutions so desired by policy makers?

A recent report by Holden and colleagues $^{1}$ attempts to answer the questions. Holden reviews and summarises the literature and brings fresh insights on parental decision-making. Behavioural economics is being harnessed by governments across the world: for example, the Behavioural Insights Team (also known as

\footnotetext{
'Department of Paediatrics, Imperial College Healthcare NHS Trust, London, UK

2Department of Paediatrics, Imperial College London, London, UK
}

Correspondence to Dr Mando Watson, Department of Paediatrics, Imperial College Healthcare NHS Trust, London, W2 1NY, UK; mando.watson@nhs.net the 'Nudge Unit'), in partnership with the Cabinet Office at 10 Downing Street, was the world's first government-backed institution for the application of behavioural sciences, to encourage payment of tax or organ donation. ${ }^{2}$ Holden's report is augmented by data derived from field work in two PEDs, interpreting the latter through the lens of 'behavioural insights' to bring a fresh perspective to our thinking. Holden's description of these behavioural biases should inform future developments that aim to reduce the high proportion of non-urgent repeat attenders.

Holden reminds us of the attraction of the A\&E 'brand'-easily understood by all, a place that delivers high-quality healthcare to anyone, at any time. The problem is starkly described:

- The number of PED attendances rose from 3.9 million in $2008 / 2009$ to 5.1 million in 2014/2015.

- Ninety per cent of PED attendances do not result in the child being admitted.

- Sixty-one per cent of parents attending PED for a non-urgent problem say they would attend again for the same problem.

- Forty-two per cent of children attending PED might not have needed to if the parents had received prior education on the self-management of illness.

With this background, it is clearly a challenge to safely divert parents to other suitable resources within the wider health system. NHS 111 was designed to support such demand but nearly a quarter of parents did not fully have confidence and trust in the first call handler which may have impacted their decision to follow the advice given. ${ }^{3}$

\section{WHY DO PARENTS CHOOSE TO COME TO THE PED?}

There are five main reasons why parents attend PED non-urgently.

1. Parental worry. Behavioural science tells us that parents' emotional state will influence their decisionmaking. If they are worried, they may overestimate the severity of their child's condition and feel less in control. The 'Think Sepsis' campaign aims to reduce mortality and morbidity of childhood sepsis. However, it has the unintended consequence of increasing parental anxiety about minor childhood illness.

2. Perceived advantages of the ED. The $\mathrm{ED}$, where parents experience a more elaborate health encounter compared with other settings (such as the use of pulse oximetry, blood tests and immediate medication) lends 'confirmation bias', in which parents will believe that they were right to judge the illness as severe. Any good patient encounter in the PED reinforces that positive perception. The 'messenger effect' suggests that patients are more likely to trust advice that comes from an authoritative source. While this gives us an explanation for the phenomenon of high PED usage, it also indicates potential solutions: the 'messenger effect' could be put to good use across the health system, for example, by implementing interventions that reinforce the GP practice as the 'trusted place' to be.

3. Perception of other healthcare services. Patients are often unaware of or do not trust alternative services such as pharmacies or out-of-hours GPs in their locality. Patients who need to make a quick decision will choose an obvious 'brand' such as the PEDso-called default bias. We may be able to shift those beliefs using behavioural insights which support a high-quality rebranding of such services.

4. Social network influence. Parents often make decisions based on what they have heard from those around them. They also make decisions based on how others may react-they want to be seen to be 'good parents'. This influence can be harnessed by healthcare systems and put to good use: peer-to-peer interaction is being used to promote healthy lifestyles and management of long-term conditions. It can also be used to influence parents' choices around minor and non-urgent illness.

5. Lack of confidence and low health literacy. We know that educational interventions which enhance health literacy can reduce healthcare demand. Holden's data indicate that parents lack confidence in assessing the severity of their child's illness and in choosing the best way to access help. Consultations in the ED rarely include written guidance on what to do next time; even verbal guidance tends to fall away when the ED gets busy. Parents in the ED may not be in an emotional state to be effective learners. ED professionals may not excel as teachers, and time and 
Box Different types of urgent care facilities in the NHS
Self-care
- NHS 111
- Pharmacy
- Your GP
Out-of-hours GP
- Minor injuries unit
- Urgent care centres
- A\&E and 999

complexity challenge the feasibility of their teaching in the ED.

\section{WHAT CAN BE DONE TO REDUCE INAPPROPRIATE ATTENDANCE?}

Across the country, a number of initiatives have been tried, including increasing access to primary care-'embedding' a GP in the PED; or educating parents in self-management; or signposting to alternative resources. Few, if any, have shown any substantial impact. The sheer range of different urgent care facilities available (see box) has created much confusion for parents.

We need a high-quality, well-designed intervention that is properly tested and can be scaled across the NHS. The design of such an intervention needs to

- emphasise the benefits of self-care

- make costs of the various services more explicit

- involve peer-support mechanisms signpost resources using a parent decision support tool.

As we learn about behavioural biases, we can further refine and adapt interventions to areas with a different demographic and range of services. How do we create 'pull', so that parents 'pull' what they need from the clinician rather than clinicians 'pushing' what we think parents need (and probably getting it wrong)? How do we strengthen parental knowledge and skills in promoting child health, providing a confidence-building balance to the rare but important 'cot death' and 'severe sepsis' messaging?

One thing is becoming clearer: parents are logical. When they attend PED they do so for the very best reasons. If we can tap into that logic, harness it and furnish it with the appropriate tools, then we have a chance to change health-seeking behaviours. To do that, we need to move away from 'we know what's best for you' and start to design our interventions with parents as real partners in the change process.

Competing interests MW is a clinical lead for Connecting Care for Children, a programme of work that supports new models of care. The programme collaborated with Ben Holden, the author of the report. $\mathrm{MB}$ is academic supervisor to Ben Holden.

Provenance and peer review Commissioned; internally peer reviewed.

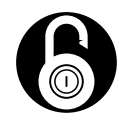

\section{OPEN ACCESS}

Open Access This is an Open Access article distributed in accordance with the Creative Commons Attribution Non Commercial (CC BY-NC 4.0) license, which permits others to distribute, remix, adapt, build upon this work non-commercially, and license their derivative works on different terms, provided the original work is properly cited and the use is non-commercial. See: http:// creativecommons.org/licenses/by-nc/4.0/

(C) Article author(s) (or their employer(s) unless otherwise stated in the text of the article) 2018. All rights reserved. No commercial use is permitted unless otherwise expressly granted.

$$
\text { D Check for updates }
$$

To cite Watson M, Blair M. Arch Dis Child 2018;103:309-310.

Received 13 November 2017

Revised 28 November 2017

Accepted 29 November 2017

Published Online First 9 January 2018

Arch Dis Child 2018;103:309-310.

doi:10.1136/archdischild-2017-314057

\section{REFERENCES}

1 The Behavioural Insights Team. http://www. behaviouralinsights.co.uk/publications/why-do-parentsbring-children-with-minor-illness-to-emergency-andurgent-care-departments/

2 The Behavioural Insights Team. Four simple ways to apply behavioural insights. http://www. behaviouralinsights.co. uk/wp-content/uploads/2015/07/BIT-Publication-EAST_ FA_WEB.pdf (accessed 8 Nov 2017).

3 Burger S, Tallett A, Maconochie I, et al. G223(P) parents' experiences of using NHS 111 as entry point to child's care pathway: piloting a new patient reported experience measure. Arch Dis Child 2016;101:A122-A123. 